\title{
Sexual adverse effects with new antidepressants
}

\author{
Shameem Mir and David Taylor
}

\begin{abstract}
Sexual dystunction is a widely recognised adverse effect of many poychotropic agents. Older antidepressants such as monoamine oxidase inhibitors and tricyclics, particularty clomipramine, cre known to engender sexual adverse effects. In depression, this problem is exacerbated by the occurrence of impotence and lowered libido as part of depressive illness itself. We examined evidence relating to more recently introduced antidepressants: selective serotonin reuplake inhlbitors, moclobemide, venlafaxine, nelazodone, mirtarcoine and reboxeline. We reviewed published triats and case reports collated from searches of Mediline, Psychlt and Micromedex from 1985 to December 1997, and confacted manufacturers of new antidepressants and requested information from them.
\end{abstract}

The true incidence of antidepressant-induced sexual dysfunction is difficult to establish. For instance, people may be understandably reluctant to voluntarily report such information. Direct questioning regarding sexual side-effects may then produce a higher estimate of the level of sexual dysfunction than by allowing individuals simply to volunteer the information. Also, psychogenic factors such as anxiety and depression are known to contribute to impairment of sexual function. Furthermore, few prospective controlled studies of sexual dysfunction have been performed, and so the literature available mainly reports single cases.

\section{Selective serotonin reuptake inhibitors}

There are a number of case reports associating SSRIs with sexual dysfunction. Indeed there are more than with other new antidepressants. However, this probably reflects more widespread use rather than a greater propensity to cause such effects. Nevertheless, it is accepted that all SSRIs cause a variety of sexual adverse effects (Gitlin, 1994). The most commonly reported effects are reduced libido, ejaculatory delay, erectile failure and anorgasmia (Hawley \& Smith, 1994).

Fluoxetine seems to be the most widely reported of the SSRIs to cause sexual impairment (it is, however, the most prescribed). In men prescribed fluoxetine there have been reports of prolonged erection (Murray \& Hooberman. 1993), involuntary sperm emission (Benazzi, 1995) and delayed ejaculation (Hong et al, 1996). Ejaculatory abnormalities (failure or delay) have also been reported with paroxetine (Charles et al, 1993, Waldinger et al, 1997). fluvoxamine (Dorevitch \& Davis, 1994), sertraline (Doogan et al, 1988) and citalopram (Baldwin \& Johnson, 1995).

In women, antidepressant-induced sexual adverse effects seem more varied. Morris (1991) reported spontaneous orgasm with fluoxetine, whereas Herman et al (1990) described delayed orgasm and anorgasmia. Fluvoxamine has been linked with an increase in libido and multiple orgasms (Dorevitch \& Davis, 1994). Citalopram appears to be the only SSRI reported to cause clitoral priapism (Berk \& Acton, 1997).

Clinical studies of the SSRIs report the incidence and nature of sexual adverse effects. However, incidence figures for the same drug vary considerably (perhaps because different methods of evaluation were used) and there are few direct comparisons between drugs. Nevertheless, given that the SSRIs by definition have the same mode of action, differences in the incidence or nature of sexual dysfunction are likely to be small, if indeed they exist.

\section{Moclobemide}

Moclobemide is a reversible inhibitor of monoamine oxidase-A (RIMA). Philipp et al (1993) describe how moclobemide led to an increase in libido in $18 \%$ of patients compared with $6.3 \%$ on doxeprin. They also described a case of moclobemide-induced sexual hyperarousal in one woman. Lauerma (1995) reported a similar case of hyperorgasmia and sexual hyperactivity in a female patient taking moclobemide. Despite relatively widespread use, particularly in Europe, we could find no other case reports linking moclobemide with sexual dysfunction. This and clinical experience suggests the incidence of sexual side-effects caused by moclobemide to be very low. Of particular note is that delayed orgasm or anorgasmia seem not to occur. 


\section{Venlafaxine}

Venlafaxine inhibits the reuptake of both noradrenaline and serotonin. The manufacturers of venlafaxine have received reports of anorgasmia, increase or decrease in libido, ejaculation disorders, impotence and priapism; most of which could be causally linked to venlafaxine. In their efficacy and safety study. Mendels et al (1993) found the difference in incidence of sexual sideeffects between placebo and the highest dose of venlafaxine ( $200 \mathrm{mg}$ a day) to be statistically significant. This may suggest a dose-related effect, further supported by Michael \& Owen (1997), who described increased libido and spontaneous erections in a man taking the maximum daily dose of venlafaxine. The number of reports of sexual side-effects with venlafaxine is fairly high considering the drug's recent introduction to the market.

\section{Nefazodone}

Nefazodone is a relatively recently marketed antidepressant. It appears to lack sexual sideeffects (Dubovsky \& Thomas, 1995); this is thought to be because of its antagonist activity at $5 \mathrm{HT}_{2}$ receptors. Preskorn (1995) compared information from different databases and found that sexual dysfunction with nefazodone was less common than with other antidepressants. For example, the placebo adjusted incidence for abnormal ejaculation/orgasm with nefazodone was $0.6 \%$ compared with paroxetine $(12.9 \%)$, sertraline (13.3\%) and venlafaxine (12\%). Indeed, intermittent nefazodone has been used in one case to treat sertraline-induced anorgasmia in a man (Reynolds, 1997), although caution is required with such a combination of drugs because of the potential of serotonin syndrome. We could find no reports associating nefazodone with sexual dysfunction. However, it is difficult to establish whether or not nefazodone is completely free from sexual side-effects as it has only been introduced to the market recently and therefore has not been widely used.

\section{Mirtazapine}

Mirtazapine increases noradrenergic and serotonergic neurotransmission via $\alpha_{2}$-auto-receptor blockade. The increased serotonergic neurotransmission is mediated only through postsynaptic $5-\mathrm{HT}_{1 \mathrm{~A}}$ receptors. This is because mirtazapine blocks $5-\mathrm{HT}_{2}$ and $5-\mathrm{HT}_{3}$ receptors. Thus, as with nefazodone one might expect a low incidence of sexual dysfunction. Indeed, clinical trials show mirtazapine to cause sexual dysfunction no more frequently than placebo and at lower frequency than amitriptyline (Montgomery, 1995). We could find no reports of sexual dysfunction related to the use of mirtazapine.

\section{Reboxetine}

Reboxetine acts as a specific noradrenaline reuptake inhibitor. Because of its lack of effect on cholinergic, adrenergic and serotonergic systems (see Table 1) a low incidence of sexual dysfunction might be expected. This seems to be borne out in clinical trials (Berzewski et al, 1997), especially at doses of $8 \mathrm{mg}$ a day or less (Mucci, 1997).

\section{Mechanism of sexual side-effects}

It can be assumed that certain drugs can be associated with specific types of sexual sideeffects. Observing which sexual side-effects are caused by a particular drug or class of drugs (not only antidepressants), and relating them to its

Table 1. Suggested mechanisms of drug-induced sexual dysfunction

\begin{tabular}{|c|c|c|}
\hline Pharmacological effect & Adverse effect & Comments \\
\hline Cholinergic blockade & May decrease or inhibit sexual function & Data inconclusive \\
\hline$\alpha_{1}$-adrenergic blockade & $\begin{array}{l}\text { Inhibition of ejaculation } \\
\text { Retrograde ejaculation } \\
\text { Priapism in men and clitoral priapism in } \\
\text { women }\end{array}$ & $\begin{array}{l}\text { Orgasm achieved but without } \\
\text { ejaculation, e.g. sertindole } \\
\text { Caused by prevention of complete } \\
\text { closure of internal urethral sphincter } \\
\text { e.g. trazodone }\end{array}$ \\
\hline Hyperprolactinaemia & $\begin{array}{l}\text { Decreased libido in both men and } \\
\text { women } \\
\text { Impotence and azoospermia in men }\end{array}$ & $\begin{array}{l}\text { e.g. typical antipsychotics, } \\
\text { risperidone, amoxapine }\end{array}$ \\
\hline $\begin{array}{l}\text { Inhibition of serotonin reuptake } \\
\text { (indirect stimulation of 5-HT } \\
\text { receptors) }\end{array}$ & $\begin{array}{l}\text { Spontaneous orgasm in women } \\
\text { Impotence and delayed ejaculation } \\
\text { in men } \\
\text { Anorgasmia in both genders }\end{array}$ & e.g. SSRls, venlafaxine, clomipramine \\
\hline
\end{tabular}


pharmacology, allows one to suggest mechanisms of sexual dysfunction (see Table 1).

\section{Treatment of drug-induced sexual dysfunction}

Drug-induced sexual dysfunction can be managed in several ways. Wherever possible, the first step should be a dose reduction. If this fails or is not feasible, the use of another drug with a lower propensity to cause sexual dysfunction would be the next step. Before remedial drug therapy (for example cyproheptadine) is considered, a drug holiday (Rothschild, 1995) may be an appropriate option.

The choice of remedial drug therapy depends on the underlying mechanism of sexual dysfunction. For example, if the adverse effect is thought to be caused by enhanced serotonergic neurotransmission, cyproheptadine may be the drug of choice. Cyproheptadine is an antihistamine with $5-\mathrm{HT}_{2}$ antagonistic activity. Waldinger (1996) described an improvement in SSRI-induced sexual dysfunction with cyproheptadine. Aizenberg et al (1995) also conclude that cyproheptadine may be beneficial in those with SSRIinduced decreased libido and anorgasmia, and Lauerma (1996) reported the successful use of cyproheptadine in treating citalopram-induced anorgasmia. Oddly, Nelson et al (1997) report the first case of using a 5- $\mathrm{HT}_{3}$ antagonist (granisitron) to treat fluoxetine-induced anorgasmia.

The use of yohimbine to treat impotence is widely recognised. Yohimbine is an $\alpha_{2}$-adrenoceptor antagonist and an $\alpha_{1}$-adrenoceptor agonist. Jacobsen (1992) has shown yohimbine to have some potential in the treatment of fluoxetine-induced orgasmic and erectile difficulties.

Unlike the remedial pharmacological treatments discussed above, the mechanism of action of amantadine in treating antidepressantinduced sexual dysfunction is not clear. Amantadine is a dopamine agonist and Shrivastava et al (1995) describe its successful use in treating SSRI-induced ejaculatory difficulties. Also, in one case amantadine has been used five to six hours before coitus to treat fluoxetineinduced anorgasmia (Balon, 1996).

\section{Therapeutic uses of sexual side-effects}

The sexual adverse effects of some antidepressants are so well known that they are used to relieve some sexual problems. For example, clomipramine and SSRIs can be used to treat premature ejaculation and trazodone is used for erectile dysfunction. Readers are directed to the review of Waldinger (1996) for a full discussion.

\section{Comment}

The true incidence and type of sexual dysfunction caused by antidepressants is difficult to establish. Furthermore, the incidence figures quoted for the same drug may vary considerably and there are few direct comparisons. Of the newer antidepressants, nefazodone and moclobemide appear to cause few sexual side-effects. The SSRIs and venlafaxine are more widely associated with sexual dysfunction. Such adverse effects, however, can have therapeutic uses. The treatment options available for antidepressant-induced sexual dysfunction are a dose reduction, changing to a different antidepressant, a drug holiday or remedial therapy. In clinical practice a dose reduction or change of drug therapy are the most common forms of treatment.

\section{References}

Aizenberg, D., Zemishlany, Z. \& Weizman, A. (1995) Cyproheptadine treatment of sexual dysfunction induced by serotonin reuptake inhibitors. Clinical Neuropharmacology, 18, 320-324.

BALDWIN, D. \& JoHNSON, N. (1995) Tolerability and safety of citalopram. Review of Contemporary Pharmacotherapy. 6. 315-325.

BALON, R. (1996) Intermittent amantadine for fluoxetineinduced anorgasmia. Journal of Sex and Marital Therapy. 22, 290-292.

BenAzZI. F. (1995) Involuntary sperm emission with fluoxetine. Canadian Journal of Psychiatry, 40, 431.

BERK, M. \& ACTON, M. (1997) Citalopram-associated clitoral priapism: a case series. International Clinical Psychopharmacology, 12, 121-122.

BerzewSKI, H., VAN MoffaerT, M. \& Gagiano, C. A. (1997) Efficacy and tolerability of reboxetine compared with imipramine in a double-blind study in patients suffering from major depressive episodes. European Neuropsychopharmacology, 7, S37-S47.

Charles, F., Weber, C. \& Weber, S. S. (1993) Paroxetine: A selective serotonin reuptake inhibiting antidepressant. Annals of Pharmacotherapy, 27, 1212-1220.

DOOGAN, D. P. \& CAILlARD, V. (1988) Sertraline: a new antidepressant. Journal of Clinical Psychiatry, 49, 4651.

DoREVITCH, A. \& DAvis, H. (1994) Fluvoxamine-associated sexual dysfunction. Annals of Pharmacotherapy. 28. 872-874.

DuBOVSKY, S. L. \& THOMAS, M. (1995) Serotonergic mechanisms and current future psychiatric practice. Journal of Clinical Psychiatry. 56 (suppl.). 38-48.

GrTuN, M. J. (1994) Psychotropic medications and their effects on sexual dysfunction: Diagnosis, biology, and treatment approaches. Journal of Clinical Psychiatry. 55. 406-413.

HAWLEY, C. \& SMrTH, V. (1994) Review of a paper entitled "Effects of antidepressants on sexual function". Medical Dialogue, 4, 1-4.

herman, J. B.. Brotman, A. W., Pollack, M. H., et al (1990) Fluoxetine-induced sexual dysfunction. Journal of Clinical Psychiatry, 51, 25-27.

Hong, S. L., Dong, H. S., Chan-Hyung, K., et al (1996) An open clinical trial of fluoxetine in the treatment of premature ejaculation. Journal of Clinical Psychopharmacology, 16, 379-382. 
JACOBSEN, F. M. (1992) Fluoxetine-induced sexual dysfunction and an open trial of yohimbine. Journal of Clinical Psychiatry, 53, 119-122.

LAUERMA, H. (1995) A case of moclobemide-induced hyperorgasmia. International Clinical Psychopharmacology, 10, 123-124.

- (1996) Successful treatment of citalopram-induced anorgasmia by cyproheptadine. Acta Psychiatrica Scandinavica, 93, 69-70.

MENDELS, J., JohnSTON, R., MATTES, J., et al (1993) Efficacy and safety of b.i.d. doses of venlafaxine in a dose response study. Psychopharmacology Bulletin, 29, 169174.

MiChAEL, A. \& OWEN, A. (1997) Venlafaxine-induced increased libido and spontaneous erections. British Journal of Psychiatry, 170, 193.

MonTGOMERY, S. A. (1995) Safety of mirtazepine: a review. International Clinical Psychopharmacology, 4, 37-45.

MORRIS, P. L. (1991) Fluoxetine and orgasmic sexua experiences. International Journal of Psychiatry in Medicine, 21, 379-382.

MuCcI, M. (1997) Reboxetine: a review of antidepressant tolerability. Journal of Psychopharmacology. 11, 533537.

MURRAY, M. J. \& HOOBERMAN, D. (1993) Fluoxetine and prolonged erection. American Journal of Psychiatry. 150, 167-168.

Nelson, E. B.. KECK, Jr, P. E. \& MCElRoy, S. L. (1997) Resolution of fluoxetine-induced sexual dysfunction with the 5- $\mathrm{HT}_{3}$ antagonist granisitron. Journal of Clinical Psychiatry, 58, 496-497.

PHILIPP, M., KOHNEN, R. \& BENKERT, O. (1993) A comparison study of moclobemide and doxepin in major depression with special reference to effects on sexual dysfunction. International Clinical Psychopharmacology. 7, 149-153.
PRESKORN, S. H. (1995) Comparison of the tolerability of bupropion, fluoxetine, imipramine, nefazodone, paroxetine, sertraline, and venlafaxine. Journal of Clinical Psychiatry, 56, 12-21.

REYNOLDS, R. D. (1997) Sertraline-induced anorgasmia treated with intermittent nefazodone (letter). Journal of Clinical Psychiatry, 58, 89.

RoTHSCHILD, A. J. (1995) Selective serotonin reuptake inhibitor - induced sexual dysfunction: efficacy of a drug holiday. American Journal of Psychiatry, 152. 1514-1516.

SHRIVASTAVA, $R$ K SHRIVASTAVA, S. OVERWEG, $N$, et a (1995) Amantadine in the treatment of sexual dysfunction associated with selective serotonin reuptake inhibitors. Journal of Clinical Psychopharmacology, 15, 83-84.

WALDINGER, M. D. (1996) Use of psychoactive agents in the treatment of sexual dysfunction. CNS Drugs, 6, 204216.

- Hengreveld, M. W. \& Zwinderman, A. H. (1997) Ejaculation-retarding properties of paroxetine in patients with primary premature ejaculation: a double-blind, randomized, dose response study. British Journal of Urology. 79, 592-595.

*Shameem Mir, Senior Clinical Pharmacist, David Taylor, Chief Pharmacist, Maudsley Hospital, Denmark Hill, London SE5 8AZ

${ }^{*}$ Correspondence

\section{$£ \quad$ Seminars in Clinical Psychopharmacology Edited by David J. King}

Psychopharmacology is a key both to the understanding of the biological basis of severe mental illness and to the rational use of drugs in clinical psychiatry. This book is an excellent introduction to an ever-expanding and fascinating subject, linking relevant basic neuropharmacology to clinical practice. It aims to bridge the gap between the theoretical basis for the mode of action of psychotropic drugs and guidance on their clinical use, and should increase interest in and understanding of the drugs widely used in clinical practice. $£ 20.00,544 p p ., 1995$, ISBN 0902241737

Available from bookshops and from the Publications Department, Royal College of Psychiatrists, 17 Belgrave Square, London SW1X 8PG (Tel. 01712352351 extension 146) 